\title{
Maternal obesity influences birth weight more than gestational diabetes
}

\author{
Eman M Alfadhli
}

\begin{abstract}
Background: Maternal obesity and gestational diabetes (GDM) are commonly encountered during pregnancy. Both conditions are independently associated with unfavorable pregnancy consequences. The objective of this study was to compare the effects of obesity and GDM on birth weight, macrosomia, and other adverse pregnancy outcomes.

Methods: This cohort study involved 531 women with a singleton pregnancy attending the Maternity and Children's Hospital, Medina, Saudi Arabia, between June 2014 and June 2015. Participants underwent a 75-g oral glucose tolerance test between 24 and 28 weeks. The International Association of Diabetes and Pregnancy Study Groups criteria were used for GDM diagnosis. BMI was assessed at the first antenatal visit, and obesity was defined as a BMI $\geq 30.0 \mathrm{~kg} / \mathrm{m} 2$. All women were followed up until delivery. Women were divided into 4 groups: non-GDM nonobese (reference group), GDM nonobese, obese non-GDM, and obese GDM. Clinical characteristics and adverse pregnancy outcomes were compared.
\end{abstract}

Results: The mean age and BMl of the participants were 30.5 years and $29.3 \mathrm{~kg} / \mathrm{m} 2$, respectively. GDM was diagnosed in $50.2 \%$ of the participants, and obesity was diagnosed in $47.8 \%$ of the participants. Obese women with GDM were the oldest and heaviest among all women. The mean birth weight increased in order among the four groups; it was highest in the infants in the obese GDM group, followed by those in the obese non-GDM, GDM nonobese and reference groups. Obesity and GDM alone or in combination were associated with higher rates of macrosomia and cesarean deliveries than the reference group. Neonatal intensive care unit (NICU) admission was higher in infants in the GDM nonobese and obese GDM groups. The frequency of low Apgar score was significantly higher in infants in the obese GDM group than in infants in the reference group.

Conclusions: Maternal obesity seems to influence birth weight more than GDM, while GDM is associated with a greater risk of admission to the NICU. The combination of both conditions is associated with the greatest risk of adverse pregnancy outcomes.

Keywords: Maternal obesity, Gestational diabetes, Birth weight, Macrosomia, Adverse pregnancy outcomes

\section{Background}

Maternal obesity and gestational diabetes (GDM) are common metabolic problems in pregnancy. Both conditions are characterized by increased insulin resistance and hyperinsulinemia and are usually diagnosed simultaneously [1].

Correspondence: alfadhli2005@yahoo.com

Medicine department, Taibah University Medical College, PO Box 344, Girls section. Universities Road, T 0966555305170 Medina, Saudi Arabia
Maternal obesity has increased considerably among women of reproductive age in the last decades in both high and middle-income countries. In 2014, the estimated percentage of overweight and obesity among pregnant women was $21.7 \%$ in India and $33 \%$ in the United States of America [2]. Likewise, the prevalence of GDM has also increased in parallel to the increase in obesity [3]. The global prevalence of GDM varies widely, from 1-50\%, depending on maternal age, race/ethnicity, socioeconomic status, screening methods, and diagnostic

(c) The Author(s). 2021 Open Access This article is licensed under a Creative Commons Attribution 4.0 International License, which permits use, sharing, adaptation, distribution and reproduction in any medium or format, as long as you give appropriate credit to the original author(s) and the source, provide a link to the Creative Commons licence, and indicate if changes were made. The images or other third party material in this article are included in the article's Creative Commons licence, unless indicated otherwise in a credit line to the material. If material is not included in the article's Creative Commons licence and your intended use is not permitted by statutory regulation or exceeds the permitted use, you will need to obtain permission directly from the copyright holder. To view a copy of this licence, visit http://creativecommons.org/licenses/by/4.0/ The Creative Commons Public Domain Dedication waiver (http://creativecommons.org/publicdomain/zero/1.0/) applies to the data made available in this article, unless otherwise stated in a credit line to the data. 
criteria [4]. Applying the International Association of Diabetes and Pregnancy Study Groups (IADPSG) criteria for GDM diagnosis has led to a marked increase in GDM prevalence [5]. The IADPSG recommendations are based on the results of the Hyperglycemia and Adverse Pregnancy Outcome (HAPO) study, which showed a continuous linear association between glucose levels and undesirable pregnancy consequences [6]. As a result, the IADPSG criteria classify GDM with a lower degree of hyperglycemia and treatment of mild GDM has been shown to reduce the frequency of adverse pregnancy outcomes $[7,8]$. Although gestational diabetes is routinely screened for and managed throughout pregnancy, obesity is usually overlooked [9]. The lack of intervention that manages obesity during pregnancy, apart from lifestyle modifications, adds to this challenge.

Maternal obesity and GDM are independently linked to unfavorable pregnancy outcomes with some variations in the influence of each condition [10-14]. GDM increases the risk of hypertensive disorders of pregnancy, polyhydramnios, and premature delivery. GDM also causes excessive fetal growth, which increases the risk of cesarean deliveries, shoulder dystocia, and neonatal hypoglycemia. Long-term complications of GDM include diabetes and cardiovascular disease in mothers and obesity and diabetes in the offspring [12]. Maternal obesity increases the risks of gestational diabetes and hypertensive disorders of pregnancy. The fetus is at risk for macrosomia, cesarean deliveries, stillbirth, and congenital anomalies. Long-term complications of maternal obesity include diabetes, hypertension, and cardiovascular disease in mothers and obesity and diabetes in the offspring [2]. Ricart et al. found obesity to affect macrosomia and cesarean delivery more than GDM [14]. In a study from Finland, the risk of macrosomia and cesarean delivery was higher in obese women with and without GDM than in normal-weight women with and without GDM [11]. The HAPO study found that the risk of cesarean delivery was higher in obese women without GDM than in nonobese women with GDM; however, macrosomia was higher in nonobese women with GDM than in obese women without GDM [12].

The purpose of this study was to compare the effects of obesity, GDM and their combination on adverse pregnancy outcomes among Saudi women using the IADP SG criteria. The primary outcomes were birth weight and macrosomia. Secondary outcomes were cesarean delivery, low Apgar score, and neonatal intensive care unit (NICU) admission.

\section{Methods}

A total of 531 pregnant women treated in the antenatal clinic at the Maternity and Children's Hospital, Medina, Saudi Arabia between June 2014 and June 2015 were included. The inclusion criteria included apparently healthy Saudi women with a singleton pregnancy. Women with pre-existing diabetes or having any chronic diseases that could affect pregnancy outcomes or women who were using any drugs that affect blood sugar were excluded.

The study was approved by the ethics committees of the Maternity and Children's Hospital, Medina, Saudi Arabia. Written informed consent was obtained from all participants.

At the first antenatal visit, demographic data, height, and weight were collected. BMI was calculated as weight/height squared $\left(\mathrm{kg} / \mathrm{m}^{2}\right)$. Obesity was defined as a BMI $\geq 30.0 \mathrm{~kg} / \mathrm{m}^{2}$ based on the World Health Organization [3]. The mean timing of the first antenatal care visit was $20.63(8.8)$ weeks.

Participants underwent a 75-g oral glucose tolerance test (OGTT) between 24 and 28 weeks of gestation. According to the IADPSG recommendations, GDM was diagnosed if any one of the cut-off values were met: fasting plasma glucose $5.1 \mathrm{mmol} / \mathrm{L}(92 \mathrm{mg} / \mathrm{dL}), 1-\mathrm{h}$ glucose $10.0 \mathrm{mmol} / \mathrm{L} \quad(180 \mathrm{mg} / \mathrm{dL})$, or 2 -h glucose $8.5 \mathrm{mmol} / \mathrm{L}(153 \mathrm{mg} / \mathrm{dL})[5]$.

Based on the results of the OGTT and BMI, women were divided into 4 groups: group 1: non-GDM nonobese (normal group); group 2: GDM nonobese; group 3: obese non-GDM; and group 4: obese GDM. Group 1 (non-GDM nonobese) was considered the reference group.

All women were followed up by an obstetrician until delivery. The women who did not have GDM were followed up monthly until the second trimester of pregnancy and then every two weeks during the third trimester. For women with GDM, antenatal visits were occurred every week. In addition, women with GDM were followed by a diabetologist, a diabetes educator, and a dietician. Self-monitoring of blood glucose was performed regularly by women with GDM to ensure adequate glycemic control. Insulin was prescribed when the glycemic target did not achieve. The recommended glycemic targets for fasting and 1-h and 2-h postprandial glucose levels were $5.2 \mathrm{mmol} / \mathrm{L}(\leq 95 \mathrm{mg} / \mathrm{dL}), 7.8 \mathrm{mmol} /$ $\mathrm{L}(\leq 140 \mathrm{mg} / \mathrm{dL})$ and $6.7 \mathrm{mmol} / \mathrm{L}(\leq 120 \mathrm{mg} / \mathrm{dL})$, respectively [6]. Obese women without GDM were followed as the reference group and not given extra recommendations on diet or exercise.

After delivery, adverse pregnancy outcomes were collected from the medical records.

Comparisons were made between the four groups with regard to clinical characteristics and adverse pregnancy outcomes. The primary outcomes included birth weight and macrosomia. Secondary outcomes were cesarean delivery, low Apgar score, and NICU admission. Macrosomia was defined as a birth weight of $4000 \mathrm{~g}$ or more, 
and an Apgar score of 7 or less at 5 minutes was considered low.

\section{Statistics}

Statistical analyses were performed using SPSS software (v 20.0; SPSS Inc., Chicago, IL). A chi-square analysis was performed to test for differences in the proportions of categorical variables. One-way ANOVA was used to determine the significance of differences between the means of continuous variables. To assess associations of obesity and GDM with pregnancy outcomes, multiple logistic regression was used. The level $P<0.05$ was taken as the cut-off value for significance.

\section{Results}

The mean age of the women was 30.5 (6.1) years, the mean BMI was $29.3(6.5) \mathrm{kg} / \mathrm{m}^{2}$, and the mean gestational age at delivery was $38.2(1.9)$ weeks. GDM was diagnosed in $50.2 \%$ of the women, of which $63.7 \%$ were obese. Obesity was documented in $47.8 \%$ of all women, of whom $66.7 \%$ had GDM. The four groups' distribution was as follows: 180 women were non-GDM nonobese, 96 were GDM nonobese, 85 were obese non-GDM, and 170 were obese GDM. Figure 1 shows the distribution percentages of the participants among the four groups.
Compared to the women in the reference group, women in the other three groups, GDM nonobese, obese non-GDM, and obese GDM, were significantly older and heavier. The mean birth weight increased in order among the groups; it was highest in the infants in the obese GDM group, followed by those in the obese nonGDM, GDM nonobese and reference groups (Fig. 2). However, significance was only reached when the birth weight of infants in the obese GDM group were compared to that of the infants in the reference group, with a 291-gm difference.

The rates of macrosomia and cesarean deliveries were significantly higher in all three groups than in the reference group. Admission to the NICU was higher in all three groups than in the reference group but only reached significance in women with GDM with and without obesity. The frequency of low Apgar score was significantly higher in infants in the obese GDM group than in infants of the reference group (Table 1).

Table 2 shows comparisons between the three nonreference groups: GDM nonobese, obese non-GDM, and obese GDM. Maternal age was significantly higher in the obese women with GDM than in the women in the GDM nonobese group and the obese non-GDM group, with no differences between the latter two groups. Obese women with GDM were significantly heavier than the

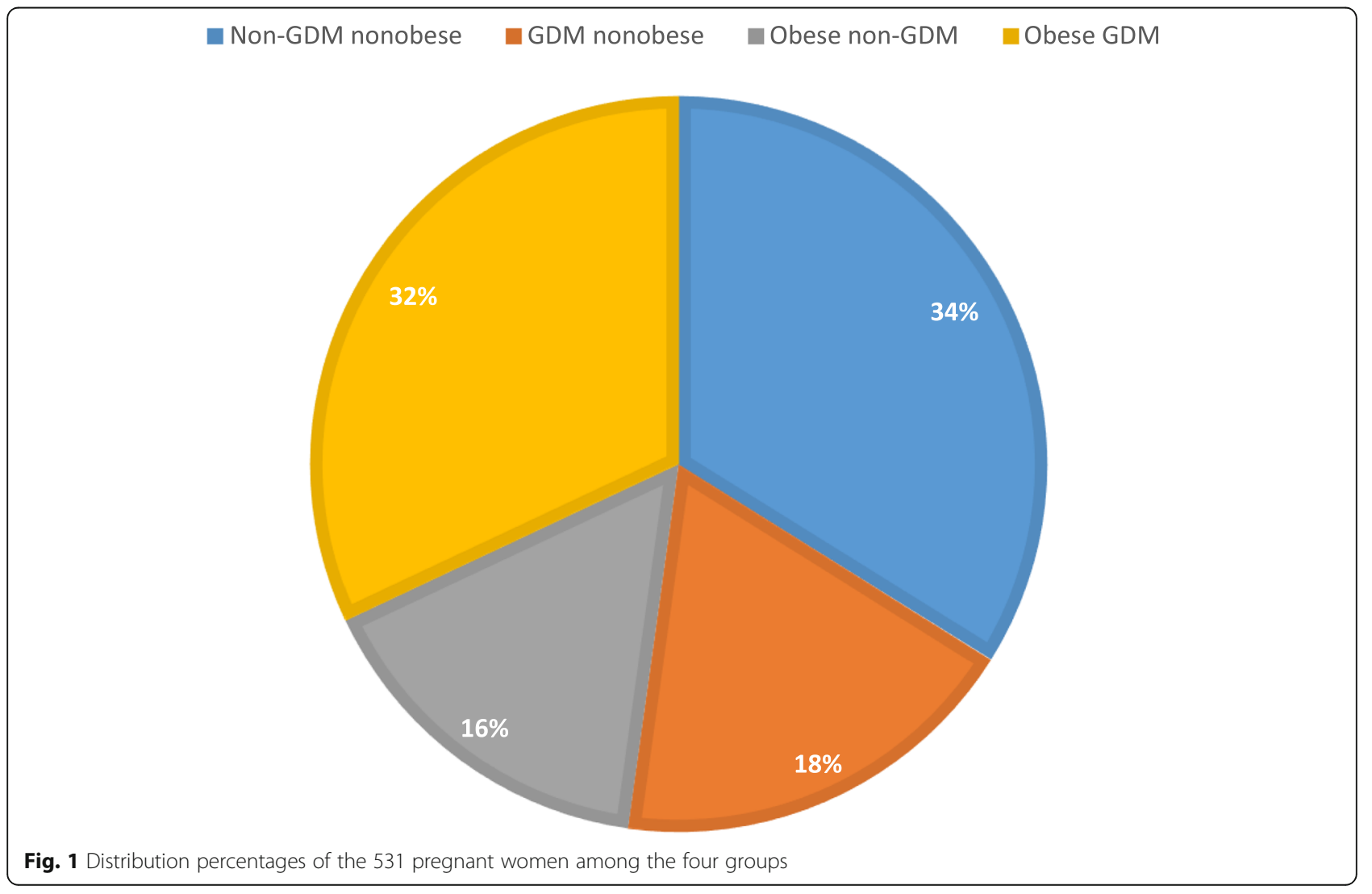




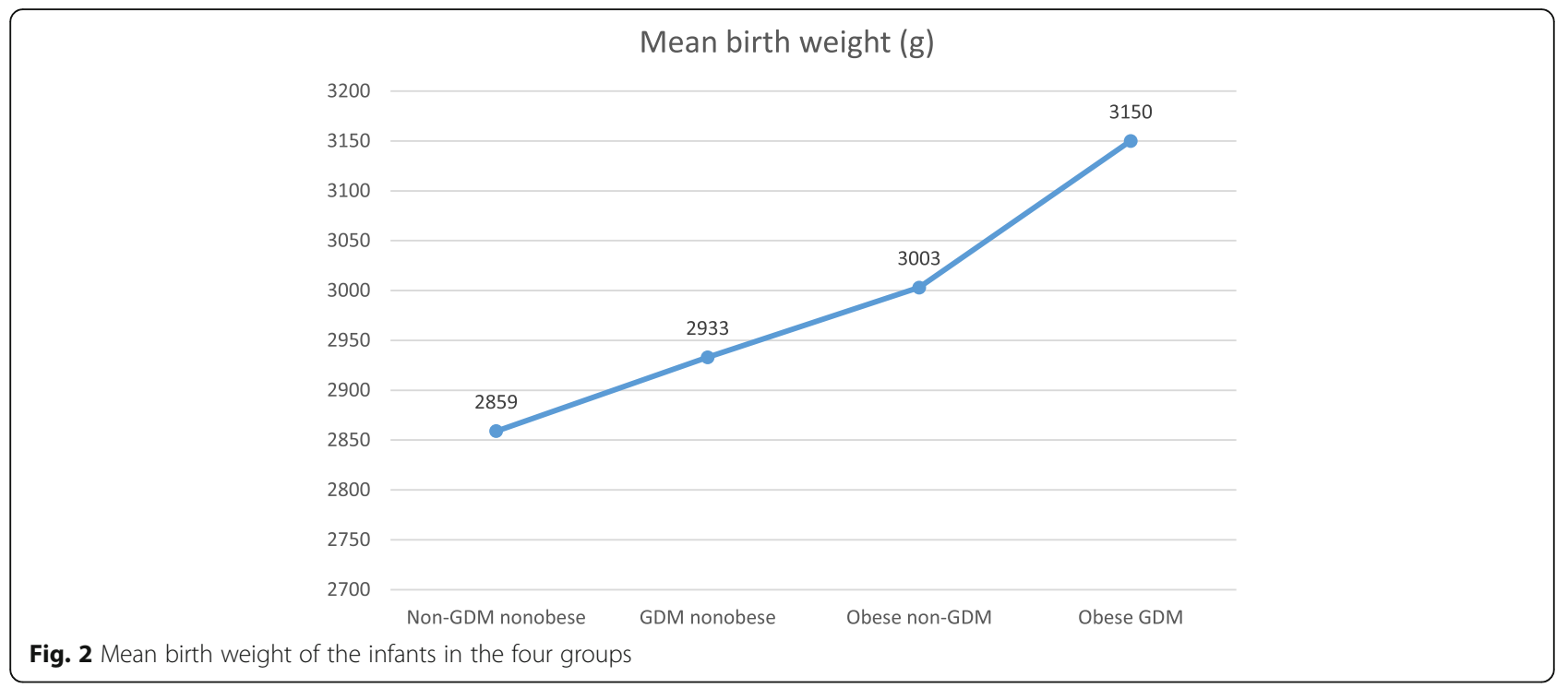

women in the other 2 groups. The mean birth weight increased in order from the GDM nonobese, obese nonGDM, and obese GDM groups but only reached significance when comparing the birth weight of infants in the obese GDM group with that of the infants in the nonobese GDM group, with a 217-gm difference. The difference in the mean birth weight of infants between the obese GDM and obese non-GDM groups was not significant. There were no significant differences in the other studied adverse pregnancy outcomes; macrosomia, cesarean delivery, low Apgar score, and NICU admission, between the three groups.

\section{Discussion}

In the current study, we found a high prevalence of maternal obesity and GDM among Saudi women: $47.8 \%$ and $50.2 \%$, respectively. This is consistent with a study from Riyadh in which the prevalence of obesity was $44 \%$ among Saudi pregnant women. In contrast, the prevalence of GDM was $15 \%$ in that study, which is much lower than the rate in this study [13]. The marked difference in GDM prevalence between the two studies is mostly related to the different methods used for GDM diagnosis. While the IADPSG criteria were used in the current study, Wahabi et al. [13] used the Carpenter and Coustan criteria [7]. This finding was demonstrated in our previous study that assessed the prevalence of GDM when applying the IADPSG vs. the Carpenter and Coustan criteria, which revealed a 2.44 -fold (144.6\%) increase when applying the IADPSG criteria: $41.5 \%$ vs. $16.9 \%$, respectively [8]. This is also consistent with the findings from other studies $[15,16]$.

In the present study, the combination of maternal obesity and GDM affected one-third of women and was associated with older maternal age, higher weight, and more adverse pregnancy outcomes than each condition alone. This is in concordance with many previous studies $[10,13,14]$.

The mean birth weight increased in order among the four groups; it was highest in the infants in the obese GDM group, followed by those in the obese non-GDM, GDM nonobese, and reference groups. However, significance was only reached when the infants in the obese GDM group were compared to the infants in the GDM nonobese and reference groups, with 217 and 291 gm differences, respectively. This is consistent with the findings from other studies $[10,11,13]$.

The risk of macrosomia and cesarean delivery were significantly increased in all three groups in comparison to that in the reference group. There was a tendency toward a higher risk of macrosomia among infants of obese women with and without GDM than among infants in the nonobese GDM group; however, the result did not reach significance. In the Finnish study, the risk of macrosomia and cesarean delivery were increased in obese women without GDM, and coexistent GDM increased the risk to a greater degree. However, normalweight women with GDM were similar to normalweight women without GDM [11]. Similarly, Ricart et al. found that obesity influenced macrosomia and cesarean section rates more than GDM [14]. Although the risk of cesarean delivery was found to be associated more with obesity than GDM in the HAPO study, macrosomia was associated more with GDM than obesity. This contradicting finding is possibly attributed to the lack of medical interventions for mild GDM in HAPO study [12].

The frequency of admission to the NICU was higher in infants in all three groups than in those in the reference group but only reached significance in GDM 
Table 1 baseline characteristics and outcomes of the four groups

\begin{tabular}{|c|c|c|c|c|}
\hline Variable & $\begin{array}{l}\text { *Non-GDM nonobese } \\
(n=180)\end{array}$ & $\begin{array}{l}\text { GDM nonobese } \\
(n=96)\end{array}$ & $\begin{array}{l}\text { Obese non-GDM } \\
(n=84)\end{array}$ & $\begin{array}{l}\text { Obese GDM } \\
(n=170)\end{array}$ \\
\hline $\begin{array}{l}\text { Age (years) } \\
\text { Mean (SD) }\end{array}$ & $28.6(6.07)$ & $31.7(6.44)$ & $31.3(5.78)$ & $33.69(5.76)$ \\
\hline$P$ value & - & 0.000 & 0.001 & 0.000 \\
\hline $\begin{array}{l}\mathrm{BMI}\left(\mathrm{kg} / \mathrm{m}^{2}\right) \\
\text { Mean }(\mathrm{SD})\end{array}$ & $24.2(3.62)$ & $26.0(3.01)$ & $34.5(4.21)$ & $36.2(5.07)$ \\
\hline$P$ value & - & 0.000 & 0.000 & 0.000 \\
\hline $\begin{array}{l}\text { Birth weight (gm) } \\
\text { Mean (SD) }\end{array}$ & $2859(0.47)$ & $2933(0.57)$ & $3003(0.58)$ & $3150(0.47)$ \\
\hline$P$ value & - & 0.333 & 0.062 & 0.000 \\
\hline $\begin{array}{l}\text { Macrosomia } \\
\text { Numbers (\%) }\end{array}$ & $0(0)$ & $3(3.1)$ & $5(6.0)$ & $7(4.1)$ \\
\hline$P$ value & - & 0.048 & 0.013 & 0.022 \\
\hline Odd ratio (OR) & - & 7.22 & 14.05 & 9.37 \\
\hline $\mathrm{Cl}$ & - & $0.37-141.52$ & $0.78-252.5$ & $0.5-176.43$ \\
\hline $\begin{array}{l}\text { Caesarian delivery } \\
\text { Numbers (\%) }\end{array}$ & $48(26.7)$ & $42(43.8)$ & $48(57.1)$ & $85(50)$ \\
\hline$P$ value & - & 0.014 & 0 & 0 \\
\hline OR & - & 2.15 & 3.69 & 2.79 \\
\hline $\mathrm{Cl}$ & - & $1.16-3.98$ & $1.97-6.91$ & $1.653-4.722$ \\
\hline $\begin{array}{l}\text { NICU Admission } \\
\text { Numbers (\%) }\end{array}$ & $25(13.9)$ & $29(30.2)$ & $20(23.8)$ & $44(25.9)$ \\
\hline$P$ value & - & 0.006 & 0.073 & 0.016 \\
\hline OR & - & 2.68 & 1.97 & 2.168 \\
\hline $\mathrm{Cl}$ & - & $1.30-5.52$ & $0.931-4.18$ & $1.143-4.115$ \\
\hline $\begin{array}{l}\text { Low Apgar Score } \\
\text { Numbers (\%) }\end{array}$ & $3(1.7)$ & $5(5.2)$ & $1(1.2)$ & $16(9.4)$ \\
\hline$P$ value & - & 0.171 & 1 & 0.006 \\
\hline OR & - & 2.82 & 1 & 1.858 \\
\hline $\mathrm{Cl}$ & - & $0.56-14.05$ & $0.09-11.2$ & $1.415-2.440$ \\
\hline
\end{tabular}

All $P$ values and ORs were compared with the reference group (non-GDM and nonobese women). ${ }^{*}$ reference group. OR Odd ratio; $C l$ confidence interval. Macrosomia, defined as a birth weight of $4000 \mathrm{~g}$ or more. Low Apgar score, defined as an Apgar score of 7 or less at 5 minutes

groups with and without obesity. This is in line with the findings from previous studies [11, 13]. The routine monitoring of infants of GDM mothers due to the concern of neonatal hypoglycemia and close observation of the infants' blood sugar may contribute to the increased risk of NICU admission. Nonetheless, in the Finnish study, the risk of NICU admission remained elevated in the infants of mothers with GDM after adjustment for neonatal hypoglycemia [11].

The frequency of low Apgar score was significantly higher in the infants of obese GDM women than in the infants of the reference group. In addition, there was a tendency toward a low Apgar score in the GDM nonobese group in comparison to the scores in the obese non-

Table 2 Comparisons between the three non-reference groups: GDM nonobese; obese non-GDM; and obese GDM

\begin{tabular}{|c|c|c|c|c|c|c|c|}
\hline \multirow[t]{2}{*}{ Mean (SD) } & \multirow{2}{*}{$\begin{array}{l}\text { Non-GDM } \\
\text { Nonobese } \\
\text { (group 1) } \\
(n=180)\end{array}$} & \multirow{2}{*}{$\begin{array}{l}\text { GDM } \\
\text { nonobese } \\
\text { (group 2) } \\
(n=96)\end{array}$} & \multirow{2}{*}{$\begin{array}{l}\text { Obese } \\
\text { non-GDM } \\
\text { (group 3) } \\
(n=85)\end{array}$} & \multirow{2}{*}{$\begin{array}{l}\text { Obese } \\
\text { GDM } \\
\text { (group 4) } \\
(n=170)\end{array}$} & \multicolumn{3}{|l|}{$P$ value } \\
\hline & & & & & $\begin{array}{l}\text { Group } 2 \\
\text { Vs. } \\
\text { Group } 3\end{array}$ & $\begin{array}{l}\text { Group } 2 \\
\text { Vs. } \\
\text { Group } 4\end{array}$ & $\begin{array}{l}\text { Group } 3 \\
\text { Vs. } \\
\text { Group 4 }\end{array}$ \\
\hline Age (year) & $28.66(6.07)$ & $31.7(6.44)$ & $31.3(5.78)$ & $33.69(5.76)$ & 0.621 & 0.011 & 0.002 \\
\hline $\mathrm{BMI}\left(\mathrm{kg} / \mathrm{m}^{2}\right)$ & $24.2(3.62)$ & $26.0(3.01)$ & $34.5(4.21)$ & $36.2(5.07)$ & 0.000 & 0.000 & 0.009 \\
\hline Birth weight (mg) & $2859(0.47)$ & $2933(0.57)$ & $3003(0.58)$ & $3150(0.47)$ & 0.488 & 0.006 & 0.061 \\
\hline
\end{tabular}


GDM group and the reference groups; however, the findings did not reach significance. This result is consistent with the findings of the Wahabi et al. and Finnish studies [11, 13]. Although Hildeń et al. found that maternal obesity and GDM are major independent risk factors for a low Apgar score, no interaction effect between GDM and obesity was found [10].

From the findings of the current study and others, one can extrapolate that obesity is associated with a higher birth weight and greater risk of macrosomia and cesarean delivery than GDM. On the other hand, GDM is associated with a greater risk of low Apgar score and admission to the NICU. However, the combination of obesity and GDM is associated with the greatest risk of adverse pregnancy outcomes [10,11,13].

Although obesity is recognized to adversely affect pregnancy, obesity during pregnancy is usually overlooked. Maternal obesity should indicate a high-risk pregnancy, particularly if combined with GDM. Lifestyle interventions, including diet and physical activity, should be recommended for obese women during pregnancy. Weight monitoring during pregnancy is required to avoid excessive weight gain. Women of reproductive age with obesity should receive facts and advice about the risks of obesity during pregnancy and be recommended to lose weight before and between pregnancies [17].

Limitations of the present study include the lack of data on prepregnancy maternal weight, which might be a contributing factor to the higher frequency of obesity in this cohort of participants. A second limitation is that we did not look at the gestational weight gain which could influence the pregnancy outcomes. Another limitation was that no intervention was provided to the obese non-GDM group, which may contribute to the higher frequency of increased birth weight of the infants in this group. The strength of this study is that we followed the participants prospectively, so we had the chance to ensure the maintenance of reasonable glycemic control among women with GDM. In addition, an OGTT was performed on all participants, so no woman with GDM was missed.

\section{Conclusions}

Maternal obesity may be associated with a higher birth weight and a greater risk of macrosomia and cesarean delivery than GDM. Conversely, GDM may be associated with a greater risk of low Apgar score and admission to the NICU. However, the combination of obesity and GDM is associated with the greatest risk for all adverse outcomes. Further studies are needed to confirm our results.

Maternal obesity should indicate a high-risk pregnancy, particularly if combined with GDM. To reduce the risk of adverse pregnancy outcomes, weight monitoring and lifestyle modification, including diet and physical activity, should be recommended for obese pregnant women. Future works are needed to study the effect of such modifications on pregnancy outcomes.

\section{Abbreviations \\ GDM: Gestational diabetes; OGTT: Oral glucose tolerance test; IADP SG: International Association of Diabetes and Pregnancy Study Groups; NICU: Neonatal intensive care unit}

\section{Acknowledgements}

I express thanks to the staff members of Maternity and Children's Hospital, Medina, Saudi Arabia, for their active support in the study.

\section{Authors' contributions}

Single author by Eman Alfadhli. The author(s) read and approved the final manuscript.

Funding

None.

Availability of data and materials

Datasets obtained and/or analyzed in this study are available from the corresponding author on reasonable request.

Ethics approval and consent to participate

The study was approved by the Ethical Committee of the Maternity and Children's Hospital, Medina, Saudi Arabia. Written informed consent was obtained from all participants.

\section{Consent for publication}

Not applicable.

\section{Competing interests}

None

Received: 15 July 2020 Accepted: 19 January 2021

Published online: 06 February 2021

\section{References}

1. Catalano PM. The impact of gestational diabetes and maternal obesity on the mother and her offspring. J Dev Origins Health Dis. 2010;1(4):208-15. $\mathrm{NIH}$ Public Access.

2. Leddy MA, Power ML, Schulkin J. The impact of maternal obesity on maternal and fetal health. Rev Obstet Gynecol. 2008:1(4):170-8.

3. $\mathrm{WHO}$ |. Obesity: preventing and managing the global epidemic. WHO; 2015 .

4. Jiwani A, Marseille E, Lohse N, Damm P, Hod M, Kahn JG. Gestational diabetes mellitus: Results from a survey of country prevalence and practices. J Maternal-Fetal Neonatal Med. 2012;25(6):600-10. Taylor \& Francis.

5. I. A. of D. and P. S. G. C. International Association of Diabetes and Pregnancy Study Groups Consensus Panel, et al. International association of diabetes and pregnancy study groups recommendations on the diagnosis and classification of hyperglycemia in pregnancy. Diabetes Care. 2010;33(3): 676-82

6. Association AD. Standards of Medical Care in Diabetes-2010. Diabetes Care. 2010:33(Supplement 1):S11-61.

7. Carpenter MW, Coustan DR. Criteria for screening tests for gestational diabetes. Am J Obstet Gynecol. 1982;144(7):768-73.

8. Alfadhli E. Gestational diabetes in Saudi women identified by the International Association of Diabetes and Pregnancy Study Group versus the former American Diabetes Association criteria: a prospective cohort study. Ann Saudi Med. 2015;35(6):428-34.

9. Jensen DM, Ovesen PG. Maternal obesity and pregnancy. Berlin Heidelberg: Springer-Verlag; 2011.

10. Hildén K, Hanson U, Persson M, Magnuson A, Simmons D, Fadl H. Gestational diabetes and adiposity are independent risk factors for perinatal outcomes: a population based cohort study in Sweden. Diabet Med. 2019; 36(2):151-7. 
11. ljäs H, Koivunen S, Raudaskoski T, Kajantie E, Gissler M, Vääräsmäki M. Independent and concomitant associations of gestational diabetes and maternal obesity to perinatal outcome: A register-based study. PLoS One. 2019;14(8):e0221549.

12. Catalano PM, et al. The hyperglycemia and adverse pregnancy outcome study: associations of GDM and obesity with pregnancy outcomes. Diabetes Care. 2012;35(4):780-6.

13. Wahabi HA, Fayed AA, Alzeidan RA, Mandil AA. The independent effects of maternal obesity and gestational diabetes on the pregnancy outcomes. BMC Endocr Disord. 2014;14:47.

14. Ricart W, et al. Body mass index has a greater impact on pregnancy outcomes than gestational hyperglycaemia. Diabetologia. 2005;48(9):1736-42.

15. Benhalima K, Hanssens M, Devlieger R, Verhaeghe J, Mathieu C. Analysis of pregnancy outcomes using the new IADPSG recommendation compared with the carpenter and coustan criteria in an area with a low prevalence of gestational diabetes. Int J Endocrinol. 2013;2013:1-6.

16. Lapolla A, Dalfrà MG, Ragazzi E, De Cata AP, Fedele D. New International Association of the Diabetes and Pregnancy Study Groups (IADPSG) recommendations for diagnosing gestational diabetes compared with former criteria: a retrospective study on pregnancy outcome. Diabet Med. 2011;28(9):1074-7.

17. Denison F, et al. Care of Women with Obesity in Pregnancy. BJOG An Int Obstet Gynaecol. 2019;126(3):e62-106.

\section{Publisher's Note}

Springer Nature remains neutral with regard to jurisdictional claims in published maps and institutional affiliations.

Ready to submit your research? Choose BMC and benefit from:

- fast, convenient online submission

- thorough peer review by experienced researchers in your field

- rapid publication on acceptance

- support for research data, including large and complex data types

- gold Open Access which fosters wider collaboration and increased citations

- maximum visibility for your research: over $100 \mathrm{M}$ website views per year

At $\mathrm{BMC}$, research is always in progress.

Learn more biomedcentral.com/submissions 